\title{
Tactile strategies for the education of tensile membrane structures; A new full-scale teaching kit for the DAD Project
}

\section{Abstract for the X International Conference on Textile Composites and Inflatable Structures - STRUCTURAL MEMBRANES 2021}

\author{
Behnejad, S Alireza ${ }^{\dagger}$ and Bassi, Saajan* \\ $\dagger$ Department of Civil and Environmental Engineering \\ University of Surrey, Guildford, Surrey GU2 7XH, United Kingdom \\ Email: a.behnejad@surrey.ac.uk
}

\begin{abstract}
Accelerated development in structural membrane technology and practice since the 1950s has increased the difficulty for fledglings to contribute to the field (Huntington, 2013). Thus, educational strategies should be employed to increase student understanding of membrane structures at undergraduate level.

This research focuses on the importance and effectiveness of tactile teaching methods in the education of tensile membrane structures at undergraduate level. Students gaining membrane construction experience and improving their understanding about tensile membrane structure design have been identified as key learning outcomes. The selection of these objectives is supported by the works of Lewis (2003) and Adriaenssens (2015).
\end{abstract}

The DAD Project requires students to deliver the Design, Assembly and Dismantling of a full-scale lattice structure, with a teaching kit comprised of prefabricated tubular steel members and connectors. Group participants develop and construct designs using the available kit (Figure 1), focussing on health and safety as well as honing creative and management skills.

The full paper will present a new case study - a new full-scale teaching kit utilised in workshops at the University of Surrey for the DAD Project (Figure 2), as well as other educational schemes using tactile strategies such as those from the University of Belgrade and Sadjad University of Technology.

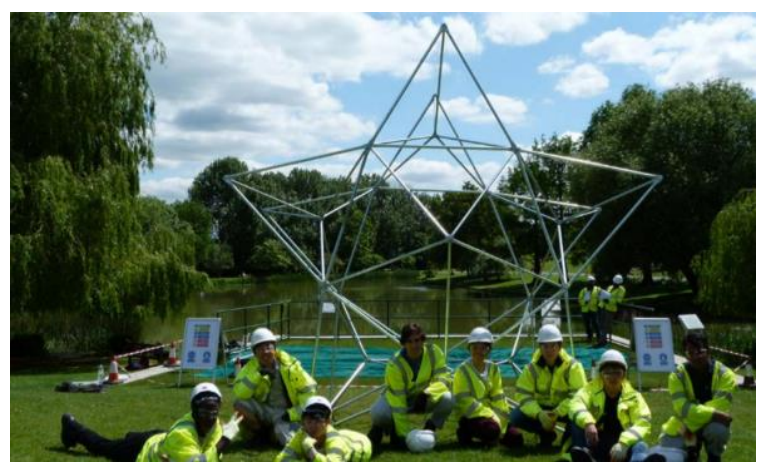

Figure 1: Example of a structure constructed by firstyear undergraduate students in June 2016

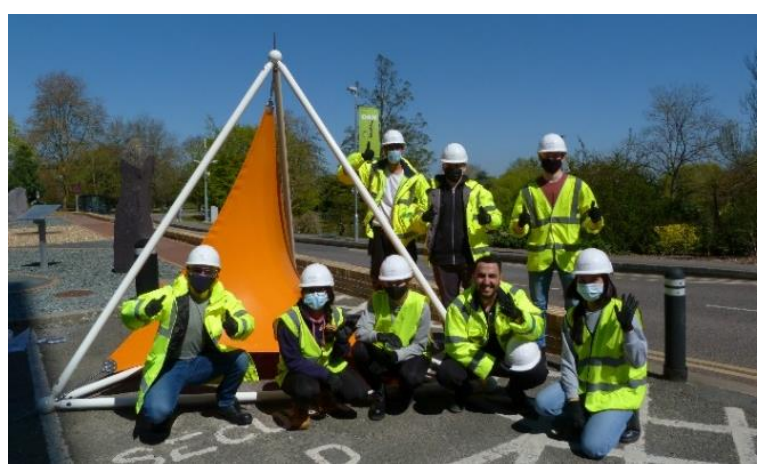

Figure 2: The new full-scale membrane teaching kit constructed by undergraduate students in April 2021

Theoretical aspects of the design and construction of membrane structures were discussed in the workshop prior to building the full-scale structure.

An appraisal from academics and students in the completion of these learning outcomes and student engagement will then follow. We expect findings to conclude the educational benefit of these workshops as well as evidence student appetite for hands-on, practical activities, particularly for membrane structures. 


\section{REFERENCES}

Adriaenssens, S. et al. (2015) 'A Project-Based Approach to Learning Form Finding of Structural Surfaces', International Journal of Space Structures, 30, pp. 297-306. doi: 10.1260/0266-3511.30.3-

4.297. (Accessed: 10 June 2021).

Huntington, G. C. (2013) Tensile Fabric Structures:Design, Analysis, and Construction. Reston,

VA: American Society of Civil Engineers doi: 10 .

Lewis, W. J. (2003) Tension structures: form and be
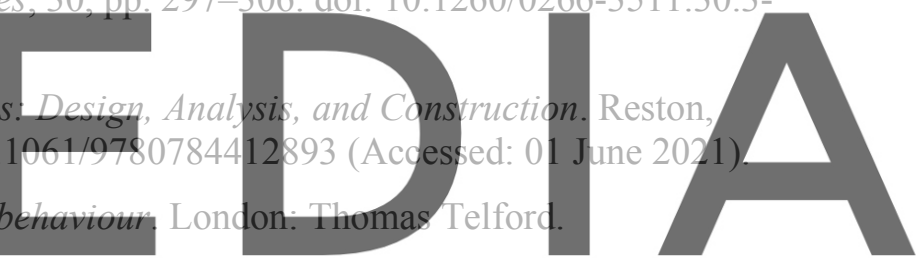

Register for free at https//www.scipedia.com to download the version without the watermark 